\title{
La deconstrucción y reconstrucción de un discurso histórico: a propósito de la mita toledana
}

\author{
Héctor Omar Noejovich \\ Pontificia Universidad Católica del Perú \\ hnoejov@macareo.pucp.edu.pe \\ Estela Cristina Salles \\ Universidad Nacional de Luján, Argentina \\ salles@generalrodriguez.com
}

\begin{abstract}
Resumen
A partir de un análisis de los orígenes de la mita toledana, se plantea una revisión del discurso histórico tradicional sobre la base de contrastar paradigmas construidos en función de las hipótesis de explotación económica de la población indígena. Desde el ángulo metodológico, se cuestionan las estimaciones aritméticas existentes y la generalización del caso de la mita potosina para interpretar el sistema de trabajo. La conclusión es que las estimaciones cuantitativas deben revisarse y que, al desagregarla de otras mitas, se ve que la de Potosí tuvo consecuencias mucho más profundas que las meramente materiales, entre ellas, la más relevante fue la desestructuración social.
\end{abstract}

Palabras clave: PERÚ, POTOSÍ, MITA, FRANCISCO DE TOLEDO.

\begin{abstract}
The article suggests a revision of the traditional historical discourse based on an analysis of the origins of the "mita toledana" that contrasts paradigms constructed on the hypotheses of economic exploitation of the indigenous population. It questions, from the methodological standpoint, the existing arithmetical estimations and the generalization of the "mita potosina" as an interpretation of the labor system. The conclusion is that the quantitative estimations must be revised and that contrasting the "mita potosina" with other "mitas", the former one had consequences that were deeper than just economic; being the disruption of social structures it's more relevant outcome.
\end{abstract}

Key words: PERÚ, POTOSÍ, MITA, FRANCISCO DE TOLEDO. 
El objetivo de nuestra propuesta es revisar el discurso histórico tradicional sobre la mita toledana ${ }^{1}$. Los discursos en las ciencias sociales tienden a seguir una línea argumentativa más o menos estable en el tiempo. En historia, la revisión de las interpretaciones de los hechos del pasado es un proceso muy lento, en parte por la fidelidad al documento que, en casos extremos, conduce a un positivismo histórico, tanto por la ausencia de crítica como por la sujeción a los paradigmas, pero en parte también por los consensos académicos, esa suerte de jurisprudencia que conduce a sujetarse a, o no atreverse a disentir de las corrientes de opinión dominantes, so pena de sufrir un ostracismo académico.

El caso de la mita toledana ${ }^{2}$, conjuntamente con el de la "caída demográfica", es un ejemplo de los paradigmas ${ }^{3}$ existentes para la interpretación de la historia de la América colonial temprana. La meta que nos proponemos es cuestionar las premisas que han servido de fundamento a aquellos. Sin duda han imperado criterios emotivos, como la Leyenda negra y la frase del Conde de Lemos: "No es oro y plata lo que va a España, sino sangre y sudor de indios". Pero sobre esos criterios se construyeron paradigmas inspirados en el materialismo dialéctico, haciendo de los aspectos materiales el fundamento de la interpretación ${ }^{4}$. A nuestro modo de ver, la mita toledana tuvo consecuencias mucho más profundas que la mera "extracción de excedente" en la que ha hecho énfasis la historiografía tradicional.

\footnotetext{
${ }^{1}$ Una versión preliminar de este artículo se presentó como ponencia al VI Congreso Internacional de Etnohistoria, Buenos Aires, noviembre 2005.

${ }^{2} \mathrm{Si}$ bien nuestro sujeto de análisis es la mita toledana, el tipo de crítica que planteamos tiene conexidad con la cuestión de la caída demográfica, expuesta en otro trabajo. Héctor Omar Noejovich, "Demografía histórica y tributo indígena. Aportes críticos", Actas del IV Congreso Internacional de Etnohistoria, ed. Franklin Pease (Lima: Fondo Editorial PCUP, 1998), 3: 253-276.

${ }^{3}$ El término es utilizado conforme los define la Real Academia de la Lengua: "Cada uno de los esquemas formales a que se ajustan las palabras nominales y verbales para sus respectivas flexiones".

${ }^{4}$ Alberto Crespo Rodas, "La mita de Potosí”. Histórica (Lima), 22 (1955-1956): 168-189; Carlos Sempat Assadourian, "La producción de la mercancía dinero en la formación del mercado interno colonial", en Ensayos sobre el desarrollo económico de México y América Latina (1500-1975), ed. Enrique Florescano (México: Fondo de Cultura Económica, 1979); "La crisis demográfica del siglo XVI y la transición del tawantinsuyu al sistema mercantil colonial”, en Población y mano de obra en América Latina, ed. Nicolás Sánchez Albornoz (Madrid: Alianza, 1985); "Acerca del cambio del dominio sobre las Indias: la mita minera del Virrey Toledo, Documentos de 1598-1571", Anuario de Estudios Americanos (Sevilla), 46 (1989): 3-68.
} 
Resulta necesario separar el diseño de una política económica de la ejecución de esa política económica ${ }^{5}$, en la cual todo programa original es susceptible de ser afectado por la corrupción generalizada, como a nuestro entender sucedió con la política instaurada por el Virrey Toledo. Esta proposición -que puede tomarse como una premisa general aplicable a otros hechos similares- distingue dos momentos de un plan: uno de concepción y formulación, otro de ejecución y resultados. La literatura sobre el tema está orientada a la ejecución, es decir, hacia la dinámica suscitada como consecuencia de la instauración de la mita toledana, haciendo una falsa correlación con la mita potosina, versión más difundida de esta "prestación obligatoria con baja remuneración" concepción, separa este concepto de la ejecución, diferenciando entre el establecimiento de la mita, la metamorfosis de la mita y la administración de la mita $^{7}$.

Nuestro trabajo está focalizado en la fase inicial del establecimiento de la mita en el siglo $\mathrm{XVI}^{8}$, aún cuando somos conscientes de que sobre las otras fases existen importantes obras relacionadas con la economía colonial ${ }^{9}$ y minera potosina ${ }^{10}$ en

\footnotetext{
${ }^{5}$ Tanto en el pasado como en el presente, existe divergencia entre los modelos de política económica, formulados a priori y los resultados verificados a posteriori, pero es un resultado de la gestión en el tiempo y no de la concepción inicial. Tampoco puede decirse que el diseñador estuviera equivocado porque los resultados no fueron los previstos, salvo que podamos establecer que debió prever la gestión, en este caso, la corrupción del sistema, sobre la cuál no tenemos dudas. Noejovich, "La política económica".

${ }^{6}$ Carlos Contreras "La minería peruana en el siglo XVIII", en El Perú en el siglo XVIII, comp. Scarlett O'phelan (Lima: Pontificia Universidad Católica del Perú, 1999). En el caso de Potosí, no solamente era una suerte de subsidio a los mineros, sino más bien una forma de mantener un mercado laboral cautivo por un año, toda vez que, por la distancias y el sistema de turnos, cada tres semanas obligaba al mitayo a quedarse en Potosí; de allí que se emplearan como mingados el resto del tiempo. El rol de subsidio de esta política se materializa con la aparición de los indios de faltriquera, como negociación entre kurakas y mineros, a lo largo del siglo XVII. Noejovich, "La política económica".

7 Jeffrey Cole, The Potosi Mita, 1573-1700. Compulsory Indian Labor in the Andes (Stanford: UP, 1985).

8 Concretamente, desde la Junta Magna de 1568, con sus antecedentes, hasta el establecimiento de la mita, con prescindencia de interpretaciones teleológicas sobre la misma.

9 Ceferino Garzón Maceda, Economía del tucumán. Economía natural y economía monetaria (Córdoba: Universidad Nacional, 1968); Assadourian, "La producción de la mercancía"; Ruggiero Romano, Consideraciones (Lima: Fociencias, 1992); Marcello Carmagnani, Formación y crisis de un sistema feudal (México: Siglo XXI, 1976); Kenneth J. Andrien, Crisis and Decline. The viceroyalty of Perú in Seventeenth Century (Albuquerque: University Press, 1985); Pedro Pérez Herrero, La América Colonial (14921763). Política y sociedad (Madrid: Síntesis, 2002), para citar algunos.

${ }^{10}$ Valentín Abecia, Mitayos en Potosi en una economía sumergida (Barcelona: Hurope, 1988); Carlos Sempat Assadourian y otros, Minería y espacio económico en los Andes.
} 
especial, las cuales aprecian la institución en un contexto temporal más amplio. En efecto, todas insisten en la metamorfosis y la administración de la mita, principalmente durante los siglos XVII y XVIII.

\section{Breve balance del discurso histórico sobre la mita}

El artículo pionero de Crespo Rodas ${ }^{11}$ enfoca la mita toledana en la evolución de esa institución por más de 100 años. Así, cuestiones como la negociación de la cuota de mitayos se mezclan en el análisis de los salarios; la denominada redención de la mita adjudica un pago personal de los indios, que en realidad era hecho por la acumulación colectiva y negociado por los capitanes de mita, lo que originó el importante fenómeno conocido como de los indios de faltriquera; además, la "evasión" por huida no solamente se daba por la mita, sino por causa del tributo en general.

Esa exposición, a nuestro juicio, se conecta con el fenómeno de la caída demográfica, al cual se refiere Assadourian ${ }^{12}$, en la medida que vincula esa disminución con la "brutal coacción" derivada del "dominio colonial", de la cual, indudablemente, la mita es el paradigma por excelencia; esta hipótesis es uno de los fundamentos más importantes de su "modelo" de la economía colonial.

Este socorrido argumento es totalmente contradictorio, dado que, aun admitiendo la mita como causal de huida ${ }^{13}$ y aceptando la división de los padrones en originarios y forasteros ${ }^{14}$ con fines de evasión de esa carga, la hipótesis de una caída demográfica y su conexión con la brutal coacción devendría en un razonamiento tautológico, dado que se apoya en los padrones tributarios, cuya variación tiene también explicaciones distintas a la mortandad; sobre la base de los padrones tributarios se ha venido sustentando la demografía histórica de la

Siglos XVI-XX (Lima: IEP, 1980); Gwendolyn Cobb, Potosí y Huancavelica. Bases económicas: 1545-1640 (La Paz: Academia Boliviana de la Historia, 1977); Joseph Barnadas, Charcas 1535-1565. Orígenes históricos de una sociedad colonial (La Paz: CIRCA, 1973); Carlos Lazo García, Economía colonial y régimen monetario Perú siglos XVI-XIX (Lima: BCR, 1992); Enrique Tandeter, Coacción y mercado: la minería de la plata en el Potosí colonial, 1692-1826 (Cuzco: Centro de Estudios Andinos "Bartolomé de las Casas, 1992), para citar algunos.

${ }^{11}$ Crespo, "La mita de Potosí".

12 Assadourian, "La crisis demográfica".

13 Crespo, "La mita de Potosí"; Teresa Cañedo-Argüelles Fábrega, Potosí: la versión aymara de un mito europeo. La minería y sus efectos en las sociedades andinas del siglo XVII. La provincia de Pacajes (Madrid: Catriel, 1993).

${ }^{14}$ Nicolás Sánchez Albornoz, Indios y tributos en el alto Perú (Lima: IEP, 1978). 
América colonial temprana ${ }^{15}$. Allí el discurso entronca con el de la "explotación económica". En ese sentido, Assadourian señala:

[...] el caso de los lupaqa, donde sabemos que cada mitayo debe entregar, al cabo de su turno, 29 pesos y medio (18 pesos ensayados), para la renta de la encomienda. Para el cálculo del jornal del mitayo optamos por la cifra media que se maneja en la relación de Potosí de 1603: 'regulados a dos pesos [corrientes] cada semana uno con otros de estos de cédula', o sea 34 pesos y dos reales durante los cuatro meses de trabajo obligatorio $[\ldots]^{16}$.

También Bakewell ${ }^{17}$ argumentó que los indios mitayos ganaban $341 / 4$ pesos corrientes y, citando un documento ${ }^{18}$, agregó que el indio mitayo pagaba 32 por año de tributo ${ }^{19}$, con un salario diario de $2 \frac{1 / 2}{2}$ reales: esto induce falazmente a crear la idea de un trabajo forzado casi gratuito. La omisión deliberada del hecho de que el "salario mitayo" servía para pagar en todo o en parte el tributo de su comunidad de origen, como veremos más adelante, distorsiona la información numérica disponible. Assadourian sostiene que: "para el mitayo el $87 \%$ de este salario monetario es pura apariencia" 20 , y así justifica que "considerando que el monto total de los jornales en el Cerro asciende a 500 mil pesos ensayados, el plus de la corpa significa un aumento del $80 \%$ en el ingreso de los trabajadores indígenas" ${ }^{21}$.

Por supuesto, todos los autores señalados hacen hincapié en las condiciones de trabajo y los efectos de la metamorfosis de la mita, además del problema de los traslados, pero el énfasis de la argumentación está puesto en aspectos numéricos, tanto para la mita como para la demografía histórica. Hay también otras distorsiones, como se observa en la siguiente cita:

${ }^{15}$ Héctor Omar Noejovich, Los albores de la economía americana (Lima: Pontificia Universidad Católica del Perú, 1996), 451 y "Demografía histórica".

${ }_{16}$ Assadourian, "La producción de la mercancía”, 262. Énfasis en el original.

${ }^{17}$ Peter Bakewell, Miners of The Red Mountain (Albuquerque, Nuevo México: UP, 1984), 105.

18 "Carta de Phelippe de Godoy a la magestad de Phelippe $3^{\circ}$ en respuesta de una carta que por su orden le escribió Juan Ruiz de Velasco" (febrero 14 de 1608), British Library, Sloane, Ms. 3055, ítem 4.

${ }^{19}$ Aceptemos la equivalencia de 1 peso corriente igual a 8 reales. Así, el tributo equivalía a 102,4 salarios $(32$ por $8 / 2,5)$

${ }^{20}$ Assadourian, "La producción de la mercancía", 262.

${ }^{21}$ Ibídem, 269. No se menciona el razonamiento aritmético que fundama tal estimación: en todo caso, y para la misma fuente, hemos estimado los salarios indígenas, no solamente mineros, incluyendo el aprovisionamiento de sal, en la suma de 78.050 reales diarios, los mismos que por 280 días laborables equivalen a 2.781 .750 pesos de a ocho, que a su vez representan 1.681 .413 pesos ensayados (1 peso ensayado igual a 450 maravedíes; un peso corriente, asumido como peso de a 8 reales, igual a 272 maravedíes). Noejovich, "La política económica", 199. 
Toledo asimismo tergiversa los hechos al afirmar que la mit' $a$ establecida en la provincia de Huamanga afectó 'hasta dos mill y quinientos indios entre cinquenta o sesenta mill que avía en aquella provincia [...]', pues fueron 3.000 indios asignados a las minas, contando la provincia de Huamanga con unos 22.000 indios tributarios. Es decir, Toledo informa al rey y al Consejo que la mit'a impuesta por él solo afecta al 4 ó 5 por ciento de la población indígena tributaria, cuando en realidad el porcentaje alcanza una amplitud del catorce por ciento. Junto a esta malicia $[\ldots]^{22}$.

Las "Ordenanzas sobre el beneficio de las minas de Huamanga y Huancavelica y régimen laboral de los indígenas", fechadas el 20 de enero de 1571, no señalan el repartimiento ${ }^{23}$. La de 3.000 indios asignados a las minas es una estimación de Lohmann ${ }^{24}$, sobre la base del "séptimo de los indios tributarios"; en el asiento con los mineros de Huancavelica, del 1 de marzo de 1573, figuran 2.200 indios solamente ${ }^{25}$.

Pero más importante es señalar que Toledo se refería a la población indígena y no a los indios tributarios, variables entre las cuales efectivamente hay $4 / 5$ por ciento y no 14. En ese sentido, otra de las deficiencias de estos cálculos es considerar solamente la incidencia de los "tributarios", cuando en los Andes las labores corresponden a la unidad doméstica, que incorpora a mujeres, adolescentes, viejos y niños, cada uno con esfuerzos distintos, pero todos como participantes tanto en las tareas de subsistencia como en la acumulación colectiva; y es sobre esa base que se debe estimar la incidencia del tributo ${ }^{26}$. Podemos discutir la interpretación, pero fundar en esos elementos la "malicia de Toledo" parecería algo aventurado.

La cuestión es que los números tomados fuera de contexto son engañosos y las aseveraciones generalizadas de testimonios, muchas veces sesgados por intereses encontrados, no han sido adecuadamente analizadas. Así, las quejas de los indios y sus defensores, que apuntan a lo social, deben contraponerse a las quejas de los mineros, que apuntan a lo material. Lo cierto y evidente es que la población

${ }^{22}$ Assadourian, "La crisis demográfica", 30; cursiva en el original, subrayado nuestro.

${ }^{23}$ Biblioteca Nacional del Perú, Ms. B511.

${ }^{24}$ Guillermo Lohmann Villena, Las minas de Huancavelica en los siglos XVI y XVII (Lima: Pontificia Universidad Católica del Perú, 1999), 104.

${ }^{25}$ Silvio Zavala, El servicio personal de los indios en el Perú (México: El Colegio de México, 1978), 225.

${ }^{26}$ Noejovich, Los albores; Estela Cristina Salles y Héctor Omar Noejovich, "Orígenes e incidencia de la mita toledana. Un enfoque alternativo" (ponencia presentada en el 51 Congreso Internacional de Americanistas, Santiago, Chile, 2003); "Los repartimientos reales: el caso de Chucuito (Perú), en el siglo XVI", Fronteras de la Historia (Bogotá), 9 (2004): 205-230. 
potosina creció notablemente desde Toledo y la economía potosina no decayó, al menos no en las medida de la cual se quejaban los empresarios ${ }^{27}$.

\section{La Corona y el trabajo forzado}

Si bien las Leyes Nuevas significaron el triunfo de las tesis lascasianas, era imperioso para la Corona impulsar la minería, especialmente la del Cerro Rico de Potosí y la de las minas de Huancavelica. Las tribulaciones por el trabajo forzado en general y por el minero en particular se vieron desde los tiempos de Pedro de La Gasca y Antonio de Mendoza, primer Marqués de Cañete; particularmente durante el gobierno de Lope García de Castro (1564-69), tras la muerte súbita del Conde de Nieva. Bajo el gobierno de este comienzan a expresarse con nitidez las dudas sobre cómo hacer que los indios trabajen en la minería. Para el caso de las minas de Huancavelica, el licenciado García de Castro consideraba que era necesario proveer de trabajadores estables a esa explotación, y para no disentir de las disposiciones que prohibían el trabajo forzado de los indios, ideó como estratagema la obligación de transportar suministros a los asentamientos mineros. De esta forma, se irían "acostumbrando" y serían fácilmente "inducidos" a trabajar en las minas, no solamente en Huancavelica, sino en otros sitios ${ }^{28}$.

Sin embargo, el Segundo Concilio Límense, convocado por García de Castro en 1567, rechazó ese argumento y tuvo como sustento el memorial del licenciado Falcón: "Representación de los daños y molestias que se hacen a los indios". De cualquier forma, si bien en la documentación es notoria la repugnancia ética de "forzar a los indios a las minas", el peso de las motivaciones económicas indujo a diversos argumentos para tranquilizar las conciencias, como en el caso del arzobispo Loayza respecto de la junta de notables convocada por Toledo y celebrada el 12 de septiembre de $1570^{29}$. Recordemos que la visita a la provincia de Chucuito a cargo de Garcí Diez de San Miguel se originó en una cédula de Lope García de Castro, fechada el 10 de diciembre de 1566.

En trabajos anteriores ${ }^{30}$ hemos considerado el sistema utilizado para el pago del tributo por parte del repartimiento de Chucuito - enviar indios a Potosí para pagar el tributo con su salario- como el antecedente de la mita potosina instaurada por Toledo. En efecto, la asignación de indios a las minas atraídos por los jornales databa de una cédula de 25 de diciembre de 1551, pero, por el Acuerdo de

\footnotetext{
${ }^{27}$ Noejovich, "La política económica".

${ }^{28}$ Lohmann, Las minas de Huancavelica, 37.

${ }^{29}$ Ibídem, 99.

${ }^{30}$ Estela Cristina Salles, "La evolución tributaria de Chucuíto, sur del Perú, siglo XVI", Journal of Iberian and Latin American Studies (Melbourne, Australia), (julio de 2000): 3955; Salles y Noejovich, "Orígenes e incidencia de la mita"; "Los repartimientos reales".
} 
Hacienda del día 5 de septiembre de 1570, se comisionó a Garcí Diez de San Miguel, encomendero de Huamanga y antiguo visitador de Chucuito ${ }^{31}$, para "convencer" a los indios de trabajar en las minas. La misión fracasó, dado que los caciques de Huamanga se negaron a autorizar a los indios a concurrir ${ }^{32}$. Con el informe de Garcí Diez, el 13 de octubre de 1570, la junta de notables respondió al virrey respecto de este punto:

[...] les parecía ser negocio conveniente que los dichos indios sean compelidos por los medios que se trata por su excelencia y los demás señores que se juntaron para la labor de las dichas minas quando no lo quieran hazer de su voluntad los dichos indios $[\ldots]^{33}$.

A los diez días, el 23 de octubre de 1570, Toledo inició su visita y un proceso que terminó con la instauración de la mita potosina. Resulta claro para nosotros que esta institución fue fruto de la maduración del plan de Toledo ${ }^{34}$ desde la Junta Magna de 1568, cuyo espíritu respecto del trabajo forzado en las minas fue sintetizado por varios autores ${ }^{35}$, que citan la Carta Real enviada por Felipe II al Virrey Toledo el 25 de septiembre de 1568:

Así es forzoso que se ocupen en esto [los indios], los cuales como quiera que está ordenado que no se les haga fuerza ni compulsión, por todos los medios justos y racionales [se vean] atraídos para que en las dichas minas haya continuo el número necesario ${ }^{36}$.

En este extremo, y frente al uso de estos argumentos para presentar el aspecto "malévolo" de Toledo, es importante resaltar la importancia del azogue de Huancavelica a la luz del procedimiento de amalgama implantado por Bartolomé Medina en 1556 para las minas de Nueva España; este era el factor tecnológico fundamental para diseñar una política minera en el Virreinato del Perú y no la mera

\footnotetext{
${ }^{31}$ Esto reforzaría nuestra hipótesis sobre el origen de la mita potosina.

${ }^{32}$ Colección de Documentos Inéditos relativos al descubrimiento, conquista y colonización de las posesiones españolas en América y Oceanía, XX: 546.

33 Archivo General de Indias -en adelante AGI- (Sevilla), Indiferente General, 857; Assadourian, "Acerca del cambio", 55; Lohmann, Las minas de Huancavelica, 101. Cursiva nuestra.

${ }^{34}$ Salles y Noejovich, "Las lecciones de la historia: repensando la política económica del Virrey Toledo" (ponencia presentada en las XIX Jornadas de Historia Económica. San Martín de los Andes, Argentina, 2004).

35 Assadourian, "Acerca del cambio"; Ignacio González Casasnovas, Las dudas de la Corona. La política de repartimientos para la minería de Potosi (Madrid: Consejo Superior de Investigaciones Científicas, 2000), entre otros.

${ }^{36}$ Demetrio Ramos, "La crisis indiana y la Junta Magna de 1568". Jahrbuch für Geschichte Lateinamerikas (Berlín), 23 (1986): 30.
} 
"explotación" de los indios", como se pretende resaltar. La organización de la fuerza de trabajo, como en la mita potosina, fue un factor subsidiario de la innovación tecnológica.

Esto se corrobora con ver el primer destino de Toledo en su periplo: Huamanga. Como consecuencia, procedió a reducir a los indios de Huamanga, a organizar el trabajo en las minas y a ordenar la fundación del poblado de Huancavelica. Ese proceso tomó ocho meses y concluyó en agosto de 1571. Anteriormente, el 25 de marzo de 1571, en carta de Francisco de Toledo a Felipe II, el virrey resalta la "vejación a los naturales" por servicios personales a los religiosos y los encomenderos, en contraposición con la defensa del sistema de reducciones y del trabajo compulsivo en las minas ${ }^{37}$.

Aparentemente, en el objetivo político de imponer la autoridad real por sobre los encomenderos y los religiosos ${ }^{38}$ ordenó la expulsión de los dominicos de Chucuito, repartimiento real ${ }^{39}$, el 7 de noviembre de 1572 , e inició la visita secreta el 8 de diciembre $^{40}$. Después de tres años de haber llegado Toledo al Perú, la hasta ese entonces inexistente mita potosina surgió como tema, luego de la visita secreta que finalizó en febrero de 1573. El primer reparto está fechado el 1 de abril de $1573^{41}$.

Podemos apreciar así que, a pesar de las instrucciones recibidas por la Junta Magna y de los antecedentes reunidos en Lima por sus predecesores, la mita potosina fue producto de un proceso de elaboración y planeamiento. En efecto, la primera mita se organizó a comienzos de 1571 para las minas de Huamanga y Huancavelica, cuyo mecanismo, tanto de explotación como de organización, fue diferente del de Potosi $^{42}$. Este parecer se contrapone con la afirmación de Assadourian:

Junto a esta malicia llama la atención, además, cómo el virrey justifica haber establecido la mit'a por decisión personal (luego de obtener el consentimiento de los religiosos, escribe, optó por imponerla de inmediato en Huamanga 'por no perder la ocasión esperando la resolución de lo que

${ }^{37}$ Zavala, El servicio personal, 70.

${ }^{38}$ Salles y Noejovich, "Las lecciones de la historia".

${ }^{39}$ Salles y Noejovich, "Los repartimientos reales".

${ }^{40}$ Héctor Omar Noejovich, "Las visitas de Chucuito en el siglo XVI: en torno a la visita secreta", en El hombre y los Andes. Ensayos en honor a Franklin Pease G-Y (Lima: Pontificia Universidad Católica del Perú; Instituto Francés de Estudios Andinos; Banco de Crédito del Perú, 2002).

${ }^{41}$ Crespo, "La mita de Potosí"; Nicolás Sánchez Albornoz, "Mita, migraciones y pueblos; variaciones en el espacio y en el tiempo. Alto Perú, 1573-1692", Historia Boliviana (Cochabamba), 3, núm. 1 (1983): 31-59.

${ }^{42}$ Las minas de azogue, cuya explotación se efectuaba por medio de "asientos", se estatizaron. 
en esta parte tenía a vuestra magestad comunicado') y cómo advierte al Consejo de Indias que, sin esperar resolución alguna de España, va a extender el sistema compulsivo a otras áreas mineras: 'yra haziendo lo mismo respecto de los mineros y indios de cada provincia donde los obiere' $[\ldots]^{43}$.

Indudablemente, Toledo encaró en primera instancia la cuestión de las minas de Huancavelica, condición necesaria para la innovación tecnológica. Pero la mita, como prestación compulsiva, no puede ser generalizada, debido a sus peculiaridades. Como afirma Sánchez Albornoz:

De estas prestaciones o mitas, la principal fue la de Potosí, por difusión, volumen y duración [...]. Otra importante mita minera fue concedida a Huancavelica [...]. Los mitayos procedieron de los pueblos de siete provincias circundantes [...]. La escala de las demás mitas, rurales, urbanas $\mathrm{u}$ otras, fue evidentemente menor y el ámbito del que se extraían los indios, más circunscrito $[\ldots]^{44}$.

Este parecer es, de suyo, mucho más acorde con la realidad, y podemos agregar que la instauración de la mita potosina se produjo dos años después de la de Huancavelica. En consecuencia, en el proceso organizativo del Plan de Toledo podemos identificar dos clases de $\operatorname{mitas}^{45}$ : la tradicional (agraria, obrajes, servicios públicos y similares) y la minera. Esta última fue subdividida en dos casos claramente diferenciados: Huancavelica y Potosí, cuyo factor de diferenciación era primordialmente la distancia que debían de recorrer los indios.

\section{La mita de Huancavelica ${ }^{46}$}

\footnotetext{
${ }^{43}$ Assadourian, "Acerca del cambio", 30. Cursiva en el original.

44 Nicolás Sánchez Albornoz, "La mita de Lima. Magnitud y procedencia", Histórica (Lima), 12, núm. 2 (1988): 193-194. Cursiva nuestra.

${ }^{45}$ Ibídem.

${ }^{46}$ Desafortunadamente, este tema específico, salvo las fuentes y referencias citadas en este texto, no hay estudios en profundidad. Carlos Contreras, "El azogue en el Perú colonial (1570-1650)" (Trabajo de grado en Historia, Pontificia Universidad Católica del Perú, Lima, 1981), no se ocupa de la mita de Huancavelica; La ciudad del mercurio. Huancavelica, 1570-1700 (Lima: IEP, 1982). La temática desarrollada por Steve Stern en Los pueblos indígenas del Perú y el desafio de la conquista española (Madrid: Alianza, 1982) es meramente referencial, con informaciones semejantes a las nuestras; su enfoque nos parece dirigido más bien a la "leyenda negra" (ibídem, 139), la "extracción de mano de obra excedente" (236) y la "base social de la explotación colonial" (278); forma parte de la historiografía desarrollada desde la perspectiva del materialismo dialéctico, que indudablemente forma parte de un época en América Latina, que integra el sujeto de nuestra discusión.
} 
Respecto de las minas de azogue, insumo fundamental en la innovación tecnológica, la incautación por parte del Estado recién se produjo en 1572, cuando el español Pedro Fernández de Velasco logró perfeccionar la técnica de la amalgama, que era conocida en el Perú, pero tenía dificultades de aplicación en Potosi $^{47}$. Como vimos, recién en 1573 se puede fechar la organización de la mita minera potosina. Antes de ello, según se desprende de las ordenanzas de Huamanga, con fecha 11 de diciembre de $1570^{48}$ se efectúo la reducción de lo indígenas por parte del mismo Toledo ${ }^{49}$. La mita minera, cuando aún las minas de azogue eran privadas, se organizó el 20 de enero de 1571 con las siguiente características principales:

[...] que los indios sean bien tratados y no vejados ni molestados y sean pagados por su trabajo.

[...] de manera que los serranos no labren minas en los yungas ni los yungas en los serranos.

[...] pagados de su trabajo y los días que se ocuparen en la ida y vuelta, de manera que después de mantenido les quede ganancia que puedan llevar para sus tierras.

[...] que no sean compelidos a la labor de las minas de más distancia de veinte leguas $[\ldots]$.

[...] es cosa notoria que al abrir las ollas en que se coció el azogue es muy dañoso, en especial para los indios que no saben cómo ha de ser, ordeno y mando que los hornos de leña no se abran hasta haber pasado veinte y cuatro horas después de que se dejaron de cebar con leña $[\ldots]^{50}$.

El programa, evidentemente, pretendía mitigar los efectos de la compulsión que implicaba y tranquilizar la conciencia. Es importante destacar: 1. el derecho a remuneración; 2. la cautela con el "temple"; 3. la generación de un "excedente" para la población indígena; 4. la protección del trabajo insalubre. Que esto no se haya cumplido posteriormente, no significa que el plan de Toledo hubiera sido meramente explotar a los indios, como sugiere la historiografía tradicional.

El salario se fijó en 3 pesos corrientes al mes para las minas de plata recién descubiertas, más 2,5 libras de carne; a los que trabajaban en las minas de azogue se les asignaba un salario de 4 pesos corrientes por mes, más la antedicha ración de carne. La duración de la mita era de dos meses, después de los cuales los mitayos regresaban a sus tierras: luego de la estatización de las minas, el jornal fue fijado

\footnotetext{
${ }^{47}$ Lohmann, Las minas de Huancavelica.

${ }^{48}$ AGI (Sevilla), "Ordenanzas de Huamanga", Lima 28 (A), D ${ }^{\circ} 63-\mathrm{e}$.

${ }^{49}$ Las reducciones forman parte de las instrucciones a los visitadores Archivo General de la Nación (Buenos Aires), S. IX.17.2.5, fols. 39v-41r.

${ }^{50}$ Biblioteca Nacional del Perú, Mss. B. 511, fols. 590v-606r.
} 
en 1 tomín más $1 \mathrm{real}^{51}$. Adicionalmente, se les abonaba el salario del viaje a sus pueblos, a razón de 5 leguas diarias; el radio de reclutamiento era de 20 leguas, de tal manera que, como máximo, el costo era de 4 jornales $^{52}$. Como veremos a continuación, esta organización tenía una estructura diferente a la instaurada en Potosí, especialmente en el desplazamiento y la alimentación.

\section{La mita potosina}

Esta mita fue definitivamente organizada hacia $1578^{53}$, cuando se estableció el número de mitayos en 13.382, en tanto que el primer repartimiento fue de 3.733 indios, en $1573^{54}$. Usualmente, la historiografía se refiere a 13.500 para la mita gruesa, conformados por un séptimo de la población tributaria en 16 provincias, con obligación de trabajar como mitayos una semana de cada tres por sus tandas, lo que para la mita ordinaria daba 4.500 mitayos con un jornal de 2,75 reales para el trabajo en los ingenios y 3,5 reales para el trabajo en las minas.

Pero el aspecto que nos parece que no está debidamente cuantificado es el del traslado $^{55}$. Dada las distancias, en un rango de 15 a 190 leguas $^{56}$, la falta de jornales y abastecimientos para los días de viaje, la incidencia de la "migración forzosa" marca una diferencia sustancial con las "otras mitas". Baste comparar con las 20 leguas de radio comarcano indicadas para Huancavelica. Los efectos de esa migración forzosa nos parecen la principal característica de la mita potosina, una de cuyas referencias puede verse en el documento publicado por Vargas Ugarte ${ }^{57}$, correspondiente a un memorial de autor anónimo de 1596 :

\footnotetext{
${ }^{51} 1$ tomín igual a 450 maravedíes/8; 1 real igual a 34 maravedíes; 1 peso corriente igual a 8 reales. Noejovich, Los albores. Esto significa 2,65 reales por día. Claramente, mucho más que los 4 pesos corrientes por mes (aproximadamente $81 / 4$ pesos corrientes por mes). Lohmann, Las minas de Huancavelica, 104; Zavala, El servicio personal, 280.

${ }^{52}$ Ibídem.

${ }^{53}$ Sánchez Albornoz, "Mita, migraciones y pueblos".

${ }^{54}$ Crespo, "La mita de Potosí".

${ }^{55}$ Véanse las Figuras 1 y 2 al final del artículo, donde se puede apreciar la incidencia de los desplazamientos -días de viaje- tanto en el tiempo insumido en la mita propiamente dicha como en la capacidad laboral de la comunidad en su conjunto.

${ }^{56} \mathrm{La}$ media estadística arroja 90.625 leguas para las 16 provincias mitayas.

${ }^{57}$ Rubén Vargas Ugarte, "Breve relación de los agravios que reciven los indios que ay desde acerca del Cuzco hasta Potosí, que es lo mejor y más rico del Perú, hecha por personas de mucha experiencia y buena conciencia y desapasionadas de todos interés temporal y que solamente desea no sea Dios N. S. Tan ofendido con tantos daños como los indios reciben en sus almas y haziendas y que la conciencia de su Majestad se descargue mejor y su Reales Rentas no sean defraudadas en nada sin que antes bayan siempre en continuación" [1596], Derecho (Lima), 10-11 (1950-1951).
} 
Las principales caussas de averse ausentado tantos indios de sus pueblos y averse huydo a diferentes partes son dos, aunque ay también algunas otras de harto momento que después se diran: La primeras es el yr a Potosí cada año tantos indios a la labor de las minas que es la que dicen la mita de Potosí. Y la segunda, el trajinar tan continuamente y con tanto exceso ${ }^{58}$.

Como se aprecia en la cita, el problema no era ni de salarios ni de explotación sobre la base de los salarios y de los tributos: el quid de la cuestión está en la movilización no solamente de los indios con sus familias ${ }^{59}$, sino del ganado y otros avituallamientos, como se aprecia en otros pasajes del documento citado que se refirieren a los indios de Chucuito que iban a Potosí:

[...] mandó D. Francisco de Toledo, Virrey que era entonces destos Reynos que cada año fuesen 2.000 y 200 y añadió 200 á los dos mill; todos estos hordinariamente ban con sus mugeres e hijos y el numero de todos ellos siempre pasa de siete mill almas, cada indio lleva por lo menos ocho o dies carneros de la tierra, y algunos pacos o alpacas para comer que es otro género de ganado; otros de más caudal llevan treynta y quarenta carneros, en ellos llevan su comida y ollas y los chuses en que duermen que son sus frazas y sus esteras para defenderse del frío, porque duermen siempre en el campo $[\ldots]$.

Lo segundo, desamparan su patria y pueblos y su ganado y chacaras y aunque algunos encomiendan lo que dejan a sus deudos, pero quando acasso vuelven lo hallan todo tan mal puesto y tan perdido que la experiencia les enseña ser lo mas acertado no volver.

Lo tercero, a la partida hazen grandes sentimientos y entristeciéndose unos con otros como gente que a pesar suyo desampara su patria y que ba a manifiesto peligro de su vida como luego se dirá y que con mucha razon teme no volverá más della $[\ldots]^{60}$.

De otro lado, la argumentación aritmética de Assadourian y Bakewell ${ }^{61}$ no considera qué hacían los mitayos de Potosí en el tiempo "libre", entre turno y turno. Es obvio que se empleaban como mingados, ganando más del doble ${ }^{62}$. Además, y siguiendo a Assadourian ${ }^{63}$, si el ingreso del mitayo era para pagar el tributo, debe tenerse en cuenta que no se trataba del tributo individual, sino del correspondiente - en todo o en parte- a la comunidad. En consecuencia, la queja

\footnotetext{
${ }^{58}$ Ibídem, 37.

${ }^{59}$ Roberto Choque Canqui, "El problema de género entre los mitayos", Historia y Cultura (La Paz, Bolivia), 26 (2000): 39-43.

${ }^{60}$ Ibídem, 33.

${ }^{61}$ Assadourian, "La producción de la mercancía"; Bakewell, Miners of The Red.

${ }^{62}$ Cole, The Potosi Mita, Noejovich, "La política económica".

${ }^{63}$ Assadourian, "La producción de la mercancía", 262.
} 
debe sustentarse más en esa "migración forzosa" y en sus consecuencias en el "despoblamiento", que no debe ser tomado como sinónimo de caída demográfica, sino más bien como "desestructuración territorial". El mismo testimonio del referido documento anónimo de 1596 despeja las dudas que pudiere haber al respecto:

[...] tienen un gran provecho en huirse a los valles y es que tienen que comer y se libran de todas estas vejaciones, y los que se quedan en Potosí acabada ya su mita y año no los fuerzan que trabajen en las minas por obligación sino que ellos de su vella gracia se alquilan y ganan dos y tres tantos que los indios de cédula y los azotan ni castigan como a los otros ni tampoco pagan al rey los treinta pesos de tasa $[\ldots]^{64}$.

La estrategia de los mitayos estaba orientada a librarse a la vez de la mita y del tributo que correspondía a la comunidad; es obvio que la perjudicada era esta última, dado que tenían que reunir los tributos de otras fuentes. Eso explicaría también las razones de los indios de faltriquera, por un lado, y de los "forasteros", por el otro: retener la mano de obra en su lugar de origen, no solamente para mantener la acumulación colectiva, sino porque el pago del tributo no quedaba asegurado con los mitayos de Potosí. Dado el sistema rotativo, el drenaje de fuerza de trabajo era constante.

\section{Hipótesis sobre el origen de la mita y de la "explotación"}

Tal como se expuso en anteriores trabajos ${ }^{65}$, el sistema de pago del tributo a la Corona con indios que iban a Potosí, primera expresión de esa modalidad, es anterior a Toledo y fue menos gravoso para los indios de Chucuito ${ }^{66}$. En aquella oportunidad los indios manifestaron que el tributo en plata (18.000 pesos ensayados) se pagaba con los 500 indios que iban a Potosí. De otro lado, el visitador Garcí Diez de San Miguel, encomendero de Huamanga y comisionado para explorar la posibilidad del trabajo "voluntario" de los indios en las minas, había sido visitador de Chucuito y es lógico suponer que tenía en mente la modalidad antes citada.

En este punto, no deja de llamarnos la atención por qué no fueron establecidas colonias de mitmakuna, dada la existencia ancestral de esa institución. En efecto,

\footnotetext{
${ }^{64}$ Esta tasa era el aporte al tributo comunitario. Vargas Ugarte, "Breve relación de los agravios", 41 .

65 Estela Cristina Salles, "Tributo y población en una encomienda real. Chuchito 15491574" (Trabajo de grado en historia, Universidad Nacional de Luján, Argentina, 2000); "La evolución tributaria de Chucuíto"; Salles y Noejovich, "Orígenes e incidencia".

${ }^{66}$ Noejovich, Los albores.
} 
desplazar gente en forma estable para reunir el tributo que correspondía a la Corona parecería una estrategia acorde con el sistema andino. Y si de asignación de tierras se trataba, podría haberse pensado en el valle de Cochabamba, como antaño ${ }^{67}$. Dejamos planteada la inquietud.

En la visión española, las visitas ordenadas por Toledo, tanto la secreta como la correspondiente a la general, incidieron en aumentar el número de indios que iban a Potosí, "para que paguen el tributo con menor vejación". Si pensamos que 500 indios pagaban 18.000 pesos ensayados, prima facie es lógico suponer que para 1.000 indios será menos costoso. El detalle está en la tasación final, que se elevó a 79.658 pesos ensayados, de los cuales, 36.400 pesos corrían a cargo de 2.200 mitayos $^{68}$, lo que representaba un promedio de $16 \frac{1}{2}$ pesos ensayados por mitayo, aproximadamente la cifra de Assadourian, pero para la mitad de la tasación del repartimiento ${ }^{69}$.

Hemos visto que en el caso de Chucuito los mitayos de esta provincia tuvieron inicialmente una tasación que significaba $271 / 4$ en pesos corrientes. Esto debemos compararlo con los salarios de los mitayos, que según Cole ${ }^{70}$ eran de $3 \frac{1}{2} 2$ reales, si trabajaban en los socavones, y de $23 / 4$ reales, si trabajaban en los molinos. De tal manera que se necesitaban entre 63 y 80 jornales para pagar el tributo; el turno obligatorio del mitayo era de una semana de cada dos, y podemos darle una equivalencia de 100 días por año ${ }^{71}$.

Obviamente, visto así, el margen para la supervivencia era exiguo. Pero Assadourian $^{72}$ omite considerar la utilización de los 200 días restantes que el

\footnotetext{
${ }^{67}$ Tampoco era un problema de distancia para los mitmakuna, como sí lo era para los mittanis. Lorandi y Rodríguez nos refieren movilizaciones de este tipo en un radio de 700 km -140 leguas aproximadamente-. Ana María Lorandi y Lorena Rodríguez, "Yanas y mitimaes. Alteraciones incaicas en el mapa étnico andino", en Los Andes cincuenta años después. Homenaje a John Murra, comp. Ana María Lorandi, Salazar-Soler y Wachtel (Lima: Pontificia Universidad Católica del Perú, 2003).

${ }^{68}$ Salles y Noejovich, "Los repartimientos reales".

${ }^{69} \mathrm{Si}$ tomamos solamente la parte de tasación que le correspondía a la Corona (50.400), el aporte de los mitayos era del $72 \%$.

${ }^{70}$ Cole, The Potosi Mita, 29.

${ }^{71} \mathrm{Si}$ tomamos en cuenta la corpa o kapcha, el ingreso anual de los trabajadores indígenas aumenta aún más. Según los cálculos de Assadourian, "La producción de la mercancía", 269 , sería el $80 \%$ de 500.000 pesos ensayados y, por consiguiente, dividido entre 13.500 mitayos, representaría 37 pesos ensayados más de ingreso anual; esos 37 pesos ensayados equivalen, en un turno anual de 100 días, a casi 5 reales diarios, con lo cual se equilibraría el menor salario percibido. Nosotros no lo hemos tomado en cuenta, pero, de hacerlo, indudablemente los ingresos del trabajador indígena aumentan.

${ }^{72}$ Assadourian, "La producción de la mercancía".
} 
mitayo estaba en Potosí. ¿Que hacía? Pues trabajaba como mingado (ver Tabla 1 al final), y así también lo suponen autores como Bakewell y Cañedo-Argüelles ${ }^{73}$.

Esa "obligación" de trabajar estaba retribuida con jornales de 8 a 12 reales para ese "tiempo sobrante" y esto representaba entre 200 y 300 pesos corrientes por año, que, aunque bajo, no era un ingreso ínfimo, y que equivalía a un salario anual de 120 a 180 pesos ensayados, no tan inferior al de un alabardero o portero de palacio, que ganaban 250 pesos ensayados (ver Tabla 2). Pero, además, los mitayos pagaban el tributo que le correspondía a la comunidad -o gran parte de él-. Visto de esta manera, y con los números que surgen del esquema teórico correspondiente a la institución de la mita, $1 / 7$ de los tributarios utilizaban $1 / 3$ de su capacidad individual de trabajo para pagar el correspondiente a todo el repartimiento. Esto significa destinar $1 / 21$ de la capacidad de trabajo del grupo para cumplir con las exigencias tributarias. ¿Dónde está la explotación medida como extracción de excedente?

\section{Reflexiones finales}

Como bien señala Gómez Rivas ${ }^{74}$, el Virrey Toledo es un clásico de la historiografía, polémico y trascendente por su obra. Es indudable que su personalidad autoritaria, propia de la época, generó juicios de valor extremos, como el de Levillier ${ }^{75}$, quién lo llamó "Supremo organizador del Perú" o el de Valcárcel $^{76}$, quién lo llamó "El gran tirano del Perú". El objetivo de Toledo, en el plan de desarrollo, se sintetiza en la siguiente cita:

Notorio es que en estos reinos del Perú no hay otra granjería ni contratación que importe a la perpetuidad y conservación de ellos si no es la labor de las minas, mediante la cual se han conservado hasta hora en la prosperidad que todos han visto porque, sin el oro y la plata que de ellas procede, no pueden tener comercio con España ni con otro ningún reino porque todo cuanto en ellos se cría y puede criar por haber dos mares den medio no se puede llevar a otras partes sin que fuesen más las costas sin comparación que el aprovechamiento y siendo esta la causa por que se poblaron, si en ellos hubiese notable disminución como la empezó a haber por faltar los metales ricos, también la habría en la doctrina y predicación

\footnotetext{
${ }^{73}$ Bakewell, Miners of The Red; Cañedo-Argüelles, Potosí.

74 León Gómez Rivas, El Virrey del Perú don Francisco de Toledo (Toledo: Instituto Provincial de Investigaciones y Estudios Toledanos; Diputación Provincial, 1994), 12.

${ }^{75}$ Roberto Levillier, Don Francisco de Toledo, supremo organizador del Perú: su vida, su obra (1515-1582), 4 t. (Madrid: Espasa-Calpe, 1935-1942).

${ }^{76}$ Luis E. Valcárcel, El virrey Toledo, gran tirano del Perú: una revisión histórica (Lima: Imprenta del Museo Nacional, 1940).
} 
evangélica y en la justicia porque faltaría en ellos la posibilidad para que Su Majestad pudiese pagar los estipendios y salarios de las personas que en ello entienden, porque asimismo cesarían los almojarifazgos y bajarían las aduanas de manera que, en lo general de todos y particular de cada uno, habría notable quiebra y disminución ${ }^{77}$.

Curiosamente, esta manifestación es congruente con las afirmaciones de Assadourian ${ }^{78}$, para interpretar la "integración y desintegración regional en el espacio colonial", desde la perspectiva del modelo de polos de crecimiento ${ }^{79}$ y del desarrollo con oferta ilimitada de mano de obra ${ }^{80}$. Efectivamente, la política de Toledo, vista a la luz de la teoría del desarrollo contemporánea, era bien "moderna". Se trataba de migrar fuerza de trabajo hacia actividades más productivas, que en la época estaban en la minería, articulada con el mercado internacional. ¿Acaso los procesos de industrialización no contemplan hoy trasladar mano de obra excedente del sector rural tradicional al sector urbano moderno? ¿Por qué satanizar a Toledo, si su política puede ser encuadrada en las políticas de desarrollo diseñadas crecientemente en los años cincuenta?

A este razonamiento se contrapone el discurso tradicional histórico aferrado a consideraciones de extracción de excedente, sustentado en cálculos aritméticos fuera de contexto (que deben ser revisados), que también menciona la mita como uno de los males, sin precisar que el caso de Potosí fue diferente del del resto del virreinato. Los costos de los traslados, supuestamente financiados por la comunidad, y el crecimiento vegetativo de la población indígena de Potosí fueron una causa probable de la deformación del sistema y la corruptela del mismo a través de los llamados indios de faltriquera: los indios no pagaban un rescate, sino que las comunidades a través de sus caciques acordaban con los mineros una operación conveniente para ambas partes.

Los mineros cobraban en plata el subsidio que representaba para ellos la asignación de mitayos y los jefes étnicos retenían a la población, tratando de evitar la migración, cuya consecuencia era la desestructuración. Complementariamente, un recurso adicional para la evasión del tributo era la "mudanza" de los pueblos, origen de los "forasteros" en los padrones. Resulta evidente que el problema mayor

77 "Ordenanzas para las minas, de plata de Potosí y Porco. Exposición de motivos" [1574], trascripción de María Justina Sarabia Viejo, en Francisco de Toledo. Disposiciones gubernativas para el virreinato del Perú. 1569-1574, ed. María Justina Sarabia Viejo (Sevilla: Escuela de Estudios Hispanoamericanos, 1986) 1:299-300.

${ }^{78}$ Carlos Sempat Assadourian, El sistema de la economía colonial (Lima: IEP, 1982), 109.

${ }^{79}$ François Perroux, La economía del siglo XX (Barcelona: Ariel, 1964).

${ }^{80}$ Arthur Lewis, "Economic Development with Unlimited Labor Supply", The Manchester School. Versión castellana en A. H. Agarwala, ed. La economía del subdesarrollo (Madrid: Tecnos, 1963), 333-373. 
era la migración forzosa impuesta por la mita potosina, a diferencia de otras mitas. De otro lado, llamar voluntarios a los indios mingados es un eufemismo: es más correcto suponer que los tales mingados eran los mismos mitayos en sus turnos libres, que además no retornaban a sus comunidades. En este sentido, todos los trabajadores deberían ser considerados involuntarios; unos en forma directa, como el caso de los mitayos, y otros en forma indirecta, como el caso de los mingados, retenidos en Potosí y obligados a buscarse su sustento. La mita potosina fue, más bien, en el largo plazo, una forma de proporcionar mano de obra estable.

Es claro que los bajos salarios no ocasionaron la "caída demográfica", sino que esta es más bien el reflejo en los padrones de la desestructuración social causada por la "migración forzosa" de la mita potosina. Por otra parte, las estimaciones que ligan a la población con los padrones tributarios y la recaudación de tributos están sustentadas en razonamientos tautológicos ${ }^{81}$; los trabajos sobre la base de modelos de población estable, como el de Boleda y Tandeter, permitirán revisar los supuestos de la demografía histórica colonial ${ }^{82}$. La metamorfosis de la mita fue fruto de la corruptela del sistema, concebido para crear un "polo de desarrollo" en derredor de la minería de Potosí, con el insumo proveniente de Huancavelica. La situación geográfica privilegiada por ambos recursos fue el pilar de la concepción del plan de Toledo: las minas de Potosí se transformaron en rentables por el procedimiento de amalgamación que utilizaba los insumos de Huancavelica y no por la explotación de los indios, todo como parte de un plan de desarrollo. Este es el discurso histórico que proponemos reconstruir.

\footnotetext{
${ }^{81}$ Noejovich, Los albores.

${ }^{82}$ Mario Boleda y Enrique Tandeter, "Dinámica demográfica en los Andes centromeridionales", Desarrollo Económico (Buenos Aires), 42, núm. 168 (enero-marzo de 2003): 589-613.
} 


\section{Tabla 1}

\section{Trabajadores indígenas en la industria minera potosina}

(1603)

\begin{tabular}{|c|c|c|}
\hline $\begin{array}{l}\text { Categoría del } \\
\text { trabajador }\end{array}$ & Actividad & Número \\
\hline Mitayos & En la mina & 4.000 \\
\hline Mingas & En la mina & 600 \\
\hline Mingas & Limpieza del mineral & 400 \\
\hline $\begin{array}{lll}\text { Indios } & \text { (hombres } & y \\
\text { mujeres) } & & \\
\end{array}$ & Clasificación del mineral a la entrada de la mina & 1.000 \\
\hline Mitayos & Molienda & 600 \\
\hline Mingas & Molienda & 4.000 \\
\hline $\begin{array}{lll}\text { Indios } & \text { (hombres } & y \\
\text { mujeres) } & & \\
\end{array}$ & Refinación de amalgamas & 3.000 \\
\hline Indios & Transporte de mineral de minas a molinos & 320 \\
\hline Indios & Transporte de sal a Potosí & 180 \\
\hline Mingas & Transporte de sal a Potosí & 1.000 \\
\hline Indios mercaderes & Transporte de madera & 1.000 \\
\hline Indios & Transporte de leña & 1.000 \\
\hline Indios & \begin{tabular}{|l}
$\begin{array}{l}\text { Transporte de estiércol de llama para } \\
\text { combustible }\end{array}$ \\
\end{tabular} & 500 \\
\hline Indios & $\begin{array}{l}\text { Transportando de estiércol de llama para } \\
\text { combustible y mezcla de amalgamas }\end{array}$ & 200 \\
\hline Indios & Elaboración y transporte de carbón & 1.000 \\
\hline Indios & Fabricación de velas & 200 \\
\hline
\end{tabular}

Fuente: Cole, The Potosí Mita, 14. 


\section{Tabla 2}

Salarios (funcionarios y empleados del gobierno) Siglo XVI

\begin{tabular}{|c|c|c|c|}
\hline LUGAR & VALOR & LUGAR & VALOR \\
\hline En palacio & & Audiencia & \\
\hline Asesor letrado & 1.000 & Oidor & 3.000 \\
\hline Protector General & 1.000 & Relator & 1.666 \\
\hline Secretario & 900 & Abogado de indios & 1.000 \\
\hline Lanza & 800 & Archivero & 600 \\
\hline Capitán de lanzas & 2.200 & Procurador de indios & 500 \\
\hline Alferes de lanzas & 1.200 & Intérprete & 400 \\
\hline Alguacil & 400 & Portero & 350 \\
\hline Intérprete & 400 & Portero & 350 \\
\hline Portero & 250 & Caja Real & \\
\hline Arcabucero & 400 & Tesorero & 2.000 \\
\hline Intérprete & 400 & Contador & 2.000 \\
\hline Portero & 250 & Factor & 2.000 \\
\hline Arcabucero & 400 & Ensayador & 400 \\
\hline Alabardero & 250 & & \\
\hline Otros oficios & & Mina de Huancavelica & \\
\hline Obrero mayor (Iglesia) & 800 & Veedor de minas & 1.000 \\
\hline Maestro mayor & 1.000 & Oficial cantero & 800 \\
\hline Contador de fábrica & 400 & Tesorero (Caja Real) & 1.000 \\
\hline Sobreestante de fábrica & 564 & Contador (Caja Real) & 800 \\
\hline Alcalde de armas & 800 & Inquisición & \\
\hline Un armero & 800 & Inquisidor & 3.000 \\
\hline Otro armero & 400 & Alguacil mayor & 1.000 \\
\hline Municipio & & Notario de secretos & 1.000 \\
\hline Alcalde de agua & 800 & Contador & 200 \\
\hline Mayordomo & 600 & Receptor & 1.000 \\
\hline $\begin{array}{lll}\text { Sargento } & \text { de } & \text { Sta. } \\
\text { Hermandad } & & \\
\end{array}$ & 281 & Alcaide & 500 \\
\hline & & Portero & 300 \\
\hline \multicolumn{4}{|c|}{ Corregimientos } \\
\hline Cercado de Lima & 1.000 & Chancay & 747 \\
\hline Xauxa & 1.400 & Huancavelica & 2.000 \\
\hline Guarochirí & 1.000 & Lucanas & 1.600 \\
\hline Cajatambo & 1.000 & Vilcasguamán & 1.000 \\
\hline Canta & 800 & Cuzco & 3.000 \\
\hline Guaylas & 1.000 & Angaraes & 1.000 \\
\hline
\end{tabular}

Fuente: Lazo García, Economía colonial y régimen monetario. 
Figura 1

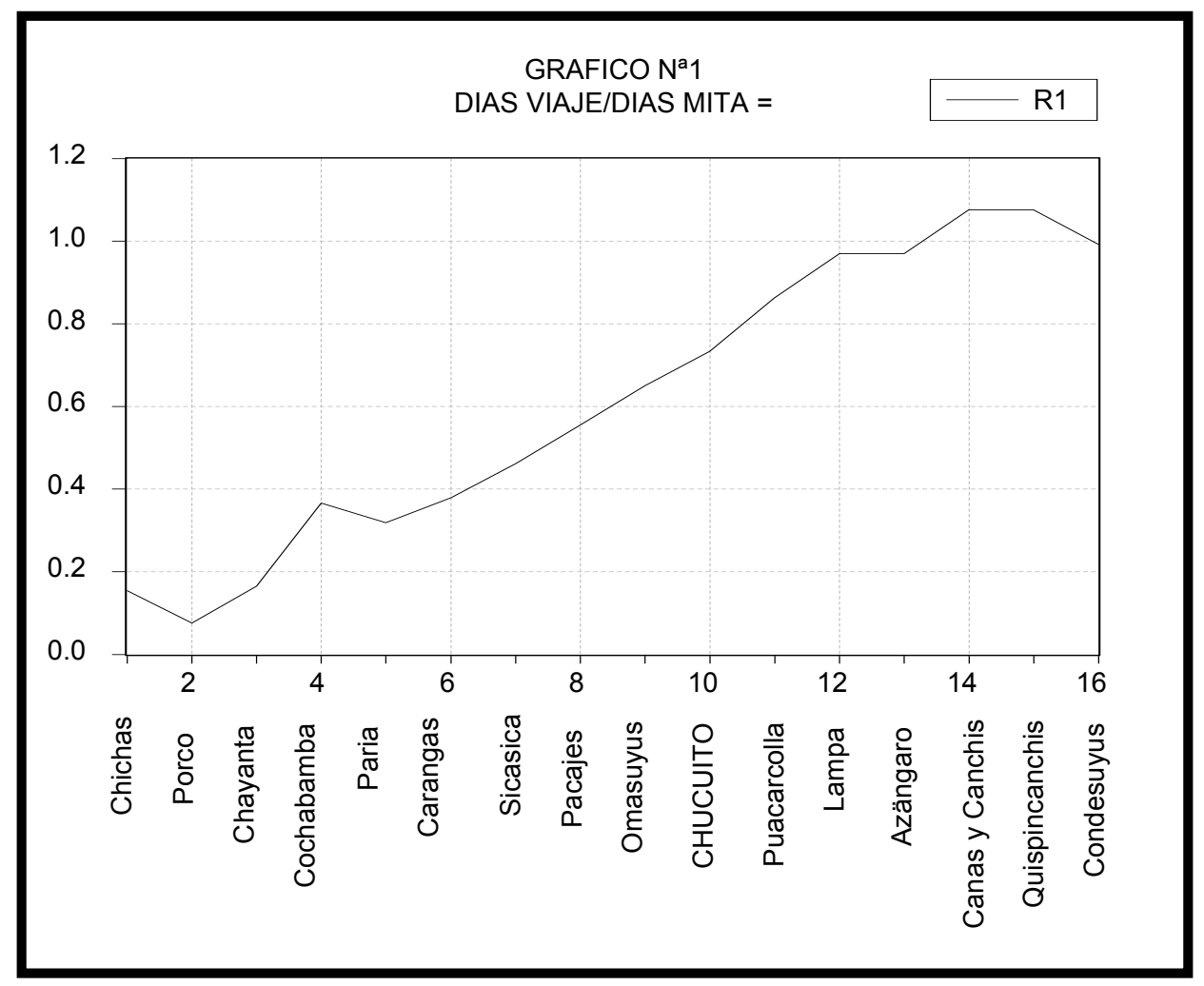

Fuente: Los autores. 
Figura 2

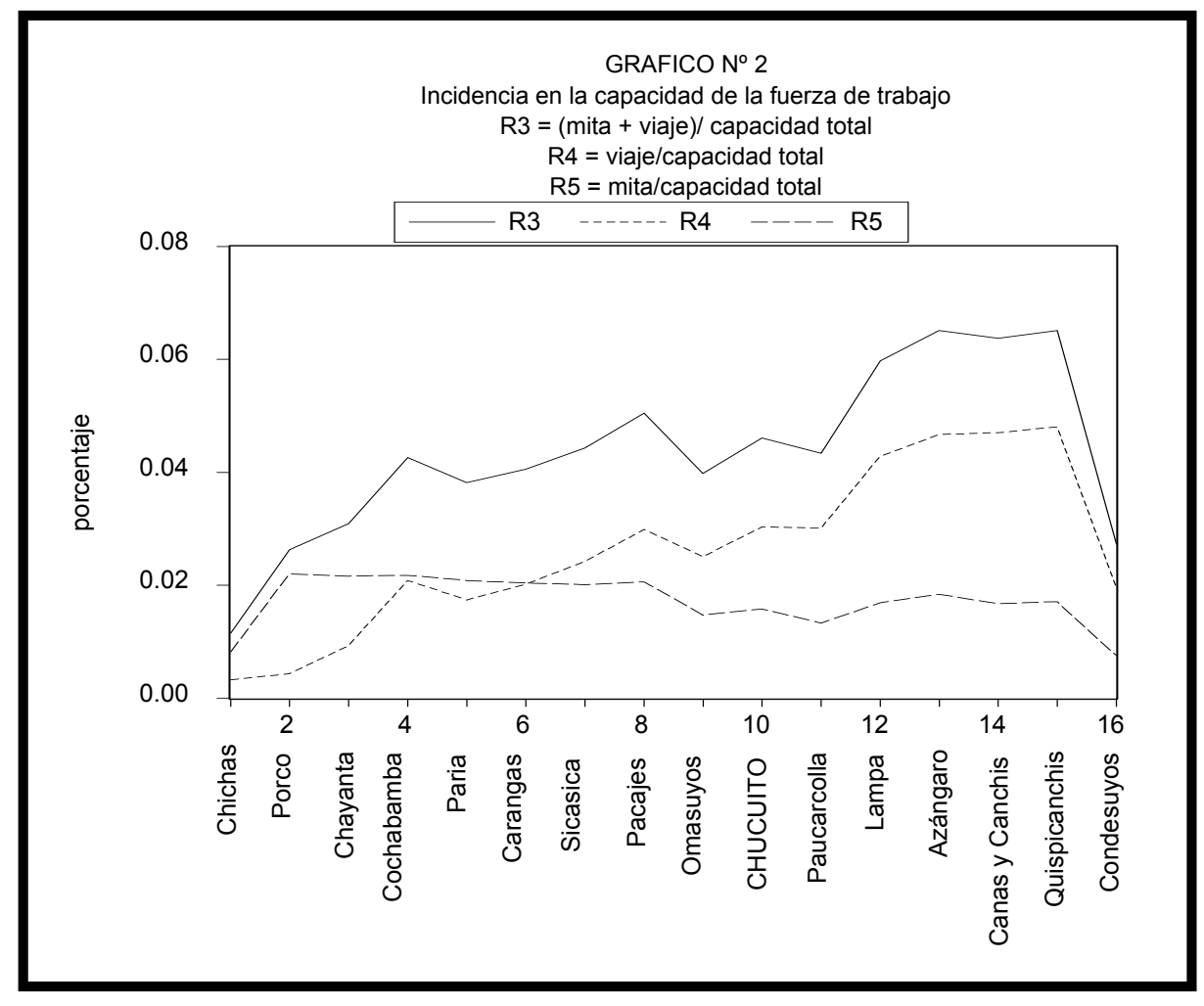

Fuente: Los autores. 


\section{Bibliografía}

\section{Fuentes primarias}

Archivo General de Indias, Sevilla, España.

Archivo General de la Nación, Buenos Aires, Argentina.

Archivo General de la Nación, Lima, Perú.

Biblioteca Nacional de Madrid.

Biblioteca Nacional del Perú, Lima.

CDIAO, Colección de Documentos Inéditos relativos al descubrimiento, conquista y colonización de las posesiones españolas en América y Oceanía.

"Yndice del Reparttimientto de Tazas de las Provincias conttenidas en este Libro hechas en tiempo del exmo. señor Don Fransisco de Toledo virrey que fue de esttos Reynos" [1577]; 1785, Archivo General de la Nación (Buenos Aires), S. IX-17-2-5.

Sarabia Viejo, María Justina, ed. Francisco de Toledo. Disposiciones gubernativas para el virreinato del Perú. 1569-1574. Sevilla: Escuela de Estudios Hispanoamericanos, 1986.

Vargas Ugarte, Rubén S. J., ed. "Breve relación de los agravios que reciven los indios que ay desde acerca del Cuzco hasta Potosí, que e lo mejor y más rico del Perú, hecha por personas de mucha experiencia y buena conciencia y desapasionadas de todos interés temporal y que solamente desea no sea Dios N. S. Tan ofendido con tantos daños como los indios reciben ens su almas y haziendas y que la conciencia de su Majestad se descargue mejor y su Reales Rentas no sean defraudadas en nada sin que antes bayan siempre en continuación" [1596], Derecho (Lima), 10-11 (1950-1951).

\section{Fuentes secundarias}

Abecia, Valentín. Mitayos en Potosí en una economía sumergida. Barcelona: Hurope, 1988.

Andrien, Kenneth J. Crisis and Decline. The viceroyalty of Perú in Seventeenth Century. Albuquerque: University Press, 1985.

Assadourian, Carlos Sempat. "La producción de la mercancía dinero en la formación del mercado interno colonial". En Ensayos sobre el desarrollo 
económico de México y América Latina (1500-1975), ed. Enrique Florescano. México: Fondo de Cultura Económica, 1979.

El sistema de la economía colonial. Lima: Instituto de Estudios Peruanos, 1982.

"La crisis demográfica del siglo XVI y la transición del tawantinsuyu al sistema mercantil colonial". En Población y mano de obra en América Latina, ed. Nicolás Sánchez Albornoz. Madrid: Alianza, 1985.

"Acerca del cambio del dominio sobre las Indias: la mita minera del Virrey Toledo. Documentos de 1598-1571". Anuario de Estudios Americanos (Sevilla), 46 (1989): 3-68.

Assadourian, Carlos Sempat y otros. Minería y espacio económico en los Andes. Siglos XVI-XX. Lima: Instituto de Estudios Peruanos, 1980.

Bakewell, Peter. Miners of the Red Mountain. Albuquerque: University Press, 1984.

Barnadas, Joseph. Charcas 1535-1565. Orígenes históricos de una sociedad colonial. La Paz: Circa, 1973.

Boleda, Mario y Enrique Tandeter. "Dinámica demográfica en los Andes centromeridionales". Desarrollo Económico (Buenos Aires), 42, núm. 168 (enero- marzo de 2003).

Cañedo-Argüelles Fábrega, Teresa. Potosí: la versión aymara de un mito europeo. La minería y sus efectos en las sociedades andinas del siglo XVII. La provincia de Pacajes. Madrid: Catriel, 1993.

Carmagnani, Marcello. Formación y crisis de un sistema feudal. México: Siglo XXI, 1976.

Choque Canqui, Roberto. Sociedad y economía colonial en el sur andino. La Paz: Hisbol, 1993

. "El problema de género entre los mitayos". Historia y Cultura (La Paz, Bolivia), 26 (2000): 39-43.

Cole, Jeffrey. The Potosi Mita, 1573-1700 Compulsory Indian Labor in the Andes. Stanford: University Press, 1985. 
Contreras, Carlos. La ciudad del mercurio. Huancavelica, 1570-1700. Lima: Instituto de Estudios Peruanos, 1982.

"El azogue en el Perú colonial (1570-1650)". Trabajo de grado en historia, Pontificia Universidad Católica del Perú, Lima, 1981.

"La minería peruana en el siglo XVIII". En El Perú en el siglo XVIII, comp. Scarlett O’phelan. Lima: Pontificia Universidad Católica del Perú, 1999.

Cobb, Gwendolyn. Potosí y Huancavelica. Bases económicas: 1545-1640. La Paz: Academia Boliviana de la Historia, 1977.

Crespo Rodas, Alberto. "La mita de Potos'”. Histórica (Lima), 22 (1955-1956): 168-189.

Díez de San Miguel, Garci. Visita a la Provincia de Chucuito de 1567, ed. Waldemar Espinoza Soriano. [1567]; Lima: Casa de la Cultura, 1964.

Garzón Maceda, Ceferino. Economía del Tucumán. Economía natural y economía monetaria. Córdoba: Universidad Nacional, 1968.

Gómez Rivas, León. El Virrey del Perú don Francisco de Toledo. Toledo: Instituto Provincial de Investigaciones y Estudios Toledanos/Diputación Provincial, 1994.

Gonzalez Casasnovas, Ignacio. Las dudas de la Corona. La política de repartimientos para la minería de Potosí. Madrid: Consejo Superior de Investigaciones Científicas, 2000.

Lazo García, Carlos. Economía colonial y régimen monetario. Perú siglo XVI-XIX. Lima: Banco Central de Reserva del Perú, 1992.

Economía colonial y régimen monetario. Perú siglos XVI-XIX. Lima: Banco Central de Reserva del Perú, 1992.

Levillier, Roberto. Don Francisco de Toledo, supremo organizador del Perú: su vida, su obra (1515-1582). 4 t. Madrid: Espasa-Calpe, 1935-1942.

Lewis, Arthur. "Economic Development with Unlimited Labor Supply". The Manchester School. Versión castellana en: A. H. Agarwala, ed. La economía del subdesarrollo, 333-373. Madrid: Tecnos, 1963. 
Lohmann Villena, Guillermo. Las minas de Huancavelica en los siglos XVI y XVII. Lima: Pontificia Universidad Católica del Perú, 1999.

Lorandi, Ana María y Lorena Rodríguez. "Yanas y mitimaes. Alteraciones incaicas en el mapa étnico andino". En Los Andes cincuenta años después. Homenaje a John Murra, comp. Ana María Lorandi, Salazar-Soler y Wachtel. Lima: Pontificia Universidad Católica del Perú, 2003.

Noejovich, Héctor Omar. Los albores de la economía americana. Lima: Pontificia Universidad Católica del Perú, 1996.

"La política económica del Virrey Toledo: un ensayo económico". Economía (Lima), 21, núm. 41(1998): 185-214.

. "Demografía histórica y tributo indígena. Aportes críticos", Actas del IV Congreso Internacional de Etnohistoria, ed. Franklin Pease (Lima: Fondo Editorial Pontificia Universidad Católica del Perú, 1998), 3: 253-276.

"Las visitas de Chucuito en el siglo XVI: en torno a la Visita Secreta". En El hombre y los Andes. Ensayos en honor a Franklin Pease G- Y. Lima: Pontificia Universidad Católica del Perú; Instituto Francés de Estudios Andinos; Banco de Crédito del Perú, 2002.

Noejovich, Héctor y Franklin Pease. "La cuestión de la plata en los siglos XVIXVII”. Histórica (Lima), 24, núm. 2 (2000): 365-413.

Perez Herrero, Pedro. La América Colonial (1492-1763). Política y sociedad. Madrid: Síntesis, 2002.

Perroux, François. La economía del siglo XX. Barcelona: Ariel, 1964.

Ramos, Demetrio. "La crisis indiana y la Junta Magna de 1568". Jahrbuch für Geschichte Lateinamerikas (Berlín), 23 (1986).

Romano, Ruggiero. Consideraciones. Lima: Fociencias, 1992.

Salles, Estela Cristina. "Tributo y población en una encomienda real. Chuchito 1549-1574". Trabajo de grado en historia, Universidad Nacional de Luján, Argentina, 2000.

."La evolución tributaria de Chucuíto, sur del Perú, siglo XVI". Journal of Iberian and Latin American Studies (Melbourne, Australia), (julio de 2000): 39-55. 
"Cuestiones sobre Chucuito en el Siglo XVI. Exacciones de la Iglesia". En América bajo los Austrias. Economía, cultura y sociedad, ed. Héctor Omar Noejovich. Lima: Pontificia Universidad Católica del Perú, 2001.

Salles, Estela Cristina y Héctor Omar Noejovich. "Orígenes e incidencia de la mita toledana. Un enfoque alternativo". Ponencia presentada en el 51 Congreso Internacional de Americanistas. Santiago, Chile, 2003.

"Las lecciones de la historia: repensando la política económica del Virrey Toledo". Ponencia presentada en las XIX Jornadas de Historia Económica. San Martín de los Andes, Argentina, 2004.

"Los repartimientos reales: el caso de Chucuito (Perú), en el siglo XVI”. Fronteras de la Historia (Bogotá), 9 (2004): 205-230.

Sánchez Albornoz, Nicolás. Indios y tributos en el Alto Perú. Lima: Instituto de Estudios Peruanos, 1978.

mita, migraciones y pueblos; variaciones en el espacio y en el tiempo. Alto Peru, 1573-1692". Historia Boliviana (Cochabamba), 3, núm. 1 (1983): 31-59.

. "La mita de Lima. Magnitud y procedencia". Histórica (Lima), 12, núm. 2 (1988): 193-197.

Stern, Steve. Los pueblos indígenas del Perú y el desafio de la conquista española. Madrid: Alianza, 1982.

Tandeter, Enrique. Coacción y mercado: la minería de la plata en el Potosí colonial, 1692-1826. Cuzco: Centro de Estudios Andinos "Bartolomé de las Casas", 1992.

Valcárcel, Luis E. El Virrey Toledo, gran tirano del Perú: una revisión histórica. Lima: Imprenta del Museo Nacional, 1940.

Whitaker, Arthur Preston. The Huancavelica Mercury Mine: Boston: Harvard University Press, 1952.

Zavala, Silvio. El servicio personal de los indios en el Perú. México: El Colegio de México, 1978.

Fecha de recepción: 9 de marzo de 2006. 
Fecha de aprobación: 14 de junio de 2006. 